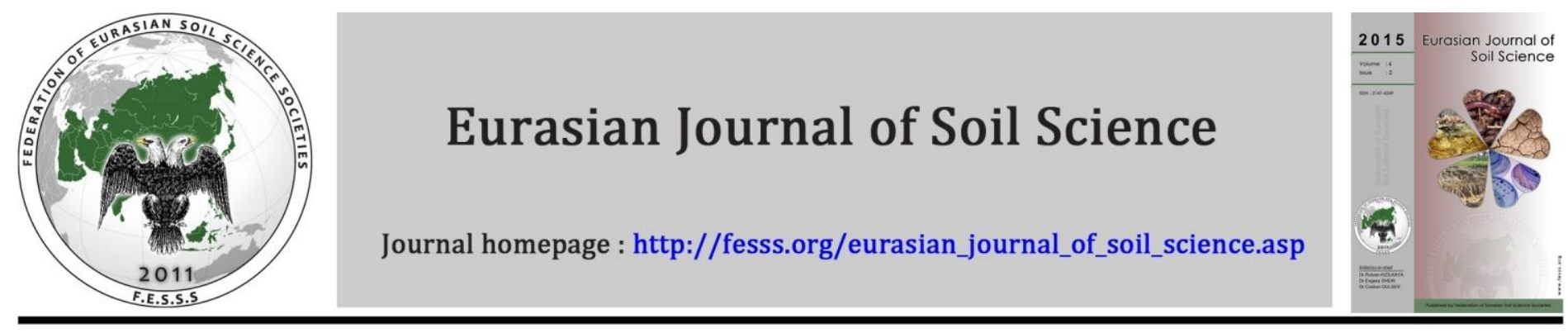

\title{
Soil organic carbon fractions as influenced by vegetation type and land management: A case study in semiarid rangelands of Hamedan, Iran
}

\author{
Khadijeh Salari Nik a,*, Mohsen Nael a, Ghasem Assadian b, \\ Ali Akbar Safari Sinegani a, Soheila Javaheri Kha a \\ a Bu-Ali Sina University, College of Agriculture, Department of Soil Science, Hamedan, Iran \\ b Faculty of Agricultural and Natural Research Center of Hamedan, Iran
}

\section{Article Info}

Received : 01.07.2014

Accepted : 27.01.2015

\begin{abstract}
Soil is an environmental component permanently changing due to the often cyclic processes of litter supply and vegetation cover. To investigate the influence of vegetation type on soil carbon fractions, six vegetation types, including rainfed wheat (RW), grasses (G), Astragallus-Bromus (A-B), Astragallus-lactuca (A-L), Astragallus-Artemisi (A-A), Astragallus-Euphorbia (A-E) were studied in similar environmental conditions in terms of parent material and slope aspect in Gonbad watershed, Hamadan. Total organic carbon (TOC), active carbon (AC), soil carbohydrates (Ch) and basal respiration (BR) were measured in surface soils $(0-15 \mathrm{~cm})$ in fall and spring. TOC, $\mathrm{CH}$, and BR were significantly greater in A-B and A-A than other covers. A-B and A-A showed higher vegetation cover and litter compared to other types. TOC and Ch in RW and G were significantly lower than other types. The highest $(711.7 \mathrm{mg} / \mathrm{kg})$ and lowest $(262.6 \mathrm{mg} / \mathrm{kg}) \mathrm{AC}$ were observed in A-B and RW, respectively. RW had lowest values of selected soil quality indicators due to tillage and cultivation. The content of TOC and AC were significantly higher in spring than autumn. Amount of BR and Ch showed no significant difference in the two seasons. Significant positive correlations were observed between soil quality indicators, these correlations were stronger in spring than in autumn. In autumn, the highest correlations were observed between AC and Ch (0.701), as well as AC and BR (0.441). In spring, significant correlations were observed between all soil quality indicators at $1 \%$ level. It was concluded that $\mathrm{AC}$ and $\mathrm{Ch}$ are the most sensitive soil quality indicators that reflect land use and vegetation type differences.
\end{abstract}

Keywords: soil quality, vegetation type, active carbon, carbohydrate

(C) 2015 Federation of Eurasian Soil Science Societies. All rights reserved

\section{Introduction}

Over the last 10 years, soil quality has been one of the topics of greatest interest in soil science. Soil quality is its capacity to be functional within limits defined by the ecosystem and land use, preserving the biological productivity and environmental quality, and promoting the health of plants, animals and human beings (Boehm and Anderson, 1997).

Soil health in rangelands is intimately linked to vegetation cover and biomass through the production and storage of SOM. Islam and Weil (2000) showed that degradation of vegetation cover and conversion of natural ecosystems to agricultural lands are the main causes of soil quality reduction.

\footnotetext{
${ }^{*}$ Corresponding author.

Bu-Ali Sina University, College of Agriculture, Department of Soil Science, Hamedan, 65174-4161 Iran

Tel.: +989183132192

E-mail address: shirvani.179m@yahoo.com

ISSN: $2147-4249$
} 
Soil organic matter is strongly influenced by vegetation cover and management, therefore it is proposed as the main indicator of soil quality and health. Changes in total soil organic matter content in response to alterations in soil management practice are difficult to detect because of the generally high background levels and natural soil variability (Haynes and Beare, 1996). Similarly, many field experiments have shown that management-induced changes in soil organic matter status occur much more rapidly in the labile pools than in organic C or total N (Graham et al., 2002). Thus, labile pools can be used as early indicators of changes in total organic matter that will become more obvious in the longer term (Gregorich et al. 1997). In addition, the labile fraction has a disproportionately large effect on nutrient-supplying capacity and structural stability of soils (Haynes and Beare, 1996).

Land management as well as soil and environmental conditions lead to the deployment of different plant communities in rangeland ecosystems, which in turn may have different effects on soil quality indicators. The main objective of this research was to investigate the influence of different vegetation covers on the quantity and quality of soil organic carbon fractions in Gonbad experimental watershed, Hamadan.

\section{Material and Methods}

Paired Gonbad watershed with a total area of nearly 290 hectares is located between longitude of $48^{\circ} 41^{\prime} 5^{\prime \prime}$ and $48^{\circ} 42^{\prime} 17^{\prime \prime}$ east and latitude of $34^{\circ} 41^{\prime} 16^{\prime \prime}$ and $34^{\circ} 42^{\prime} 31^{\prime \prime}$ north, in $28 \mathrm{~km}$ south east of Hamedan. The watershed consists of two sub-basins: in control sub-basins no grazing management is applied, while in protected sub-basin, grazing has been restricted to a very short period in late autumn since 2002. Average annual precipitation and average annual temperature in the area are $304.4 \mathrm{~mm}$ and $5.9^{\circ} \mathrm{C}$, respectively (Anonymous, 2008). The soil cover of the watershed consists of Typic Calcixerepts, Typic Haploxerepts and Lithic Xerorthents (Bahrami, 2012).

Preliminary stratification of vegetation cover was accomplished based on satellite images and field observations. Subsequently, five different vegetation types, of which grasses (G), Astragalus-Bromus (A-B), Astragalus-Artemisia (A-A), Astragalus-Lactuca (A-L) in protected sub-basin, and Astragalus-Euphorbia (AE) in control sub-basin, were selected. Plant characteristics of rangeland vegetation types are presented in Table 1. In addition, a formerly cultivated hilly land outside the watershed, now under rainfed wheat farming (RW) was selected as a nonpasture vegetation type. All of the six vegetation types were similar in terms of soil parent materials and slope aspect.

Soil and plant sampling were conducted in mid-autumn 2012, and late spring 2013. Three plot $\left(1 * 1 \mathrm{~m}^{2}\right)$ were studied in each vegetation type. The coverage of total canopy, annual and perennial grasses, annual and perennial forbs, and shrubs, as well as the coverage of surface gravel ( $>2 \mathrm{~mm}$ ), litter and bare soil were measured in each plot. Moreover, the annual growth of plant cover, partitioned to the five mentioned classes, was determined. Three surface soil samples $(0-15 \mathrm{~cm})$ were collected from each plot.

Total soil organic carbon (Walkley and Black, 1934), basal respiration (Isermeyer, 1952), soil active carbon (Weil et al., 2003), and soil carbohydrates (Dubois et al., 1956) were determined. A factorial experimental design with two factors, vegetation type (6 levels) and time (2 levels), was conducted. Prior to statistical analysis, data were normalized, if required.

\section{Results and Discussion}

Selected vegetation characteristics of the rangeland vegetation types, including canopy cover, annual production and species diversity, are presented in Table 1.

Table 1. Selected vegetation characteristics of different plant communities

\begin{tabular}{|c|c|c|c|c|c|c|c|c|c|c|c|c|c|c|}
\hline & \multicolumn{4}{|c|}{ Canopy(\%) } & \multirow[b]{2}{*}{$\mathrm{AF}$} & \multirow[b]{2}{*}{$\mathrm{PF}$} & \multicolumn{6}{|c|}{ Production $\left(\mathrm{g} / \mathrm{m}^{2}\right)$} & \multicolumn{2}{|c|}{ Species Diversity } \\
\hline & $\mathrm{T}$ & Sh & AG & $P G$ & & & $\mathrm{~T}$ & Sh & AG & $P G$ & $\mathrm{AF}$ & $\mathrm{PF}$ & Simpson & $\begin{array}{c}\text { Shannon- } \\
\text { Wiener }\end{array}$ \\
\hline $\mathrm{G}$ & 29 & 5.8 & 2.6 & 0.5 & 1.7 & 11.1 & 17.76 & 0.2 & 0 & 0.06 & 0.03 & 16.9 & 0.242 & 0.598 \\
\hline$A-E$ & 22.7 & 7.4 & 3.5 & 6 & 0.7 & 4.2 & 49.4 & 17.2 & 3.6 & 18.2 & 0 & 10.4 & 0.75 & 2.246 \\
\hline A-L & 28.3 & 11.8 & 10.3 & 0.8 & 0 & 4.5 & 45 & 35.8 & 1.5 & 0 & 0 & 7.8 & 0.752 & 2.241 \\
\hline$A-B$ & 61.4 & 21.2 & 11.1 & 20.7 & 0.3 & 10.5 & 81.8 & 41.2 & 2.9 & 10.9 & 2.2 & 15.9 & 0.769 & 2.645 \\
\hline A-A & 62.3 & 28.5 & 5.7 & 24.2 & 2.2 & 1.8 & 106.3 & 76.9 & 1.9 & 20.2 & 0 & 7.3 & 0.586 & 1.922 \\
\hline
\end{tabular}

$\mathrm{T}=$ Total, $\mathrm{Sh}=$ Shrub, $\mathrm{AG}=$ Annual Grass, $\mathrm{PG}=$ Perennial Grass, $\mathrm{AF}=$ Annual Forb, $\mathrm{PF}=$ Perennial Forb 
Selected properties of surface soil $(0-15 \mathrm{~cm})$ and surface cover in six vegetation types are presented in Table 2.

Table 2. Comparison of selected soil properties and surface cover in six vegetation types

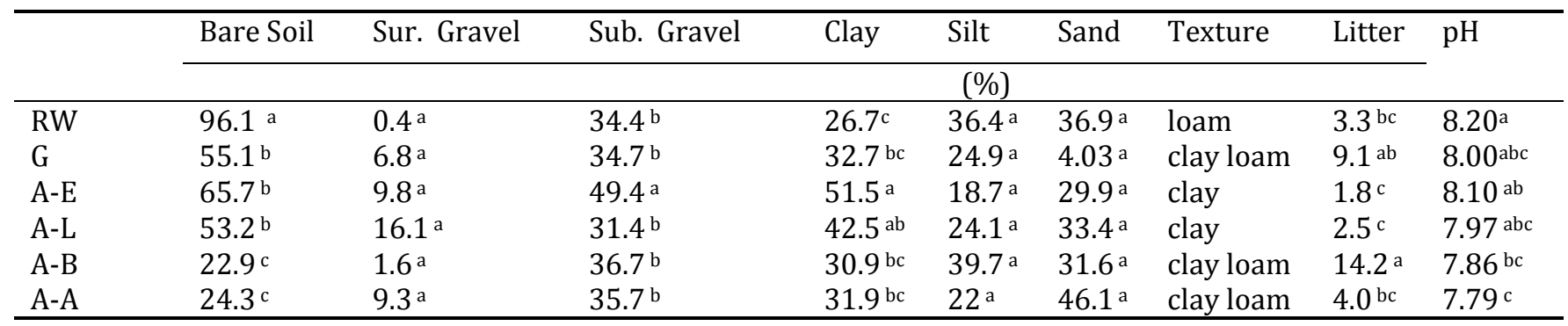

\section{Total organic carbon}

Soil organic carbon content is significantly different between vegetation types, so that it is highest in A-B and A-A (1.59 and $1.53 \%$, respectively), and lowest in RW and G (0.80 and $0.81 \%$, respectively) sites (Figure $1 \mathrm{~A})$; analogously, A-B and A-A had highest canopy cover, litter cover and species diversity (Table 1 and 2). Species diversity in rangeland ecosystems has direct effect on fodder production and soil organic carbon (Franzluebbers et al. 2001; Franzluebbers, 2010). In RW site, the plant residue inputs are low since no organic fertilizer is applied; moreover, all residues are removed from this fragile agroecosystem by grazing. On the other hand, the decomposition of SOC is highest in this site due to moldboard plowing. Many researchers have showed that cultivation reduces soil organic matter (Parton et al., 1987; Spohn and Giani, 2011). The seasonal variation of total soil organic carbon was statistically significant between vegetation types (Figure 1B), so that SOC was significantly higher in spring time due to the improved vegetation cover, as well as root and microbial activity.
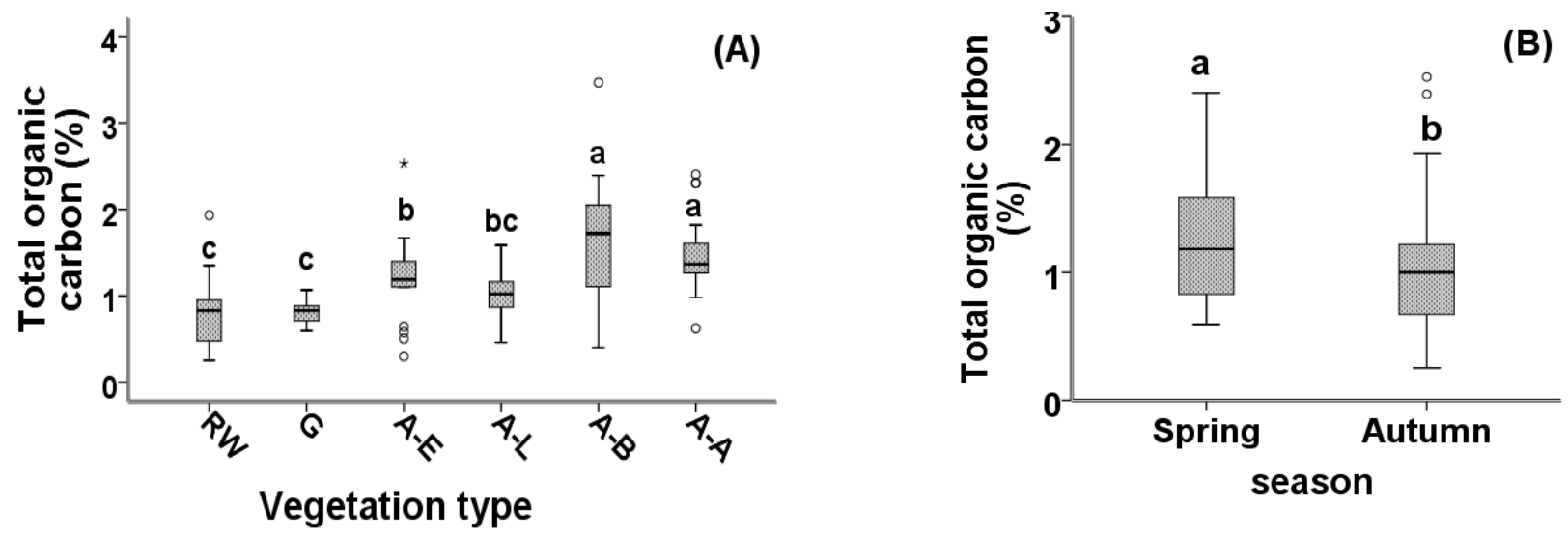

Figure 1. The effects of vegetation type (A) and season (B) on total soil organic carbon.

\section{Active carbon}

Active carbon is said to be an indicator of initial soil degradation and changes in management practices (Weil et al., 2003). Soil active carbon content was significantly highest in A-B $(711.7 \mathrm{mg} / \mathrm{kg})$, and lowest $(262.6$ $\mathrm{mg} / \mathrm{kg}$ ) in RW site. Active carbon in A-A and A-L (557.8 and $522.2 \mathrm{mg} / \mathrm{kg}$, respectively) sites are significantly greater than A-E and G (395 and $375.4 \mathrm{mg} / \mathrm{kg}$, respectively) sites (Figure 2A). Astragalus-Bromus site is rich in grass species with high amounts of readily decomposable root residues and exudates; on the other hand, highest active carbon content in A-B is in line with the highest total soil organic carbon of this site. Active carbon content was significantly higher in spring than autumn (Figure 2B). 

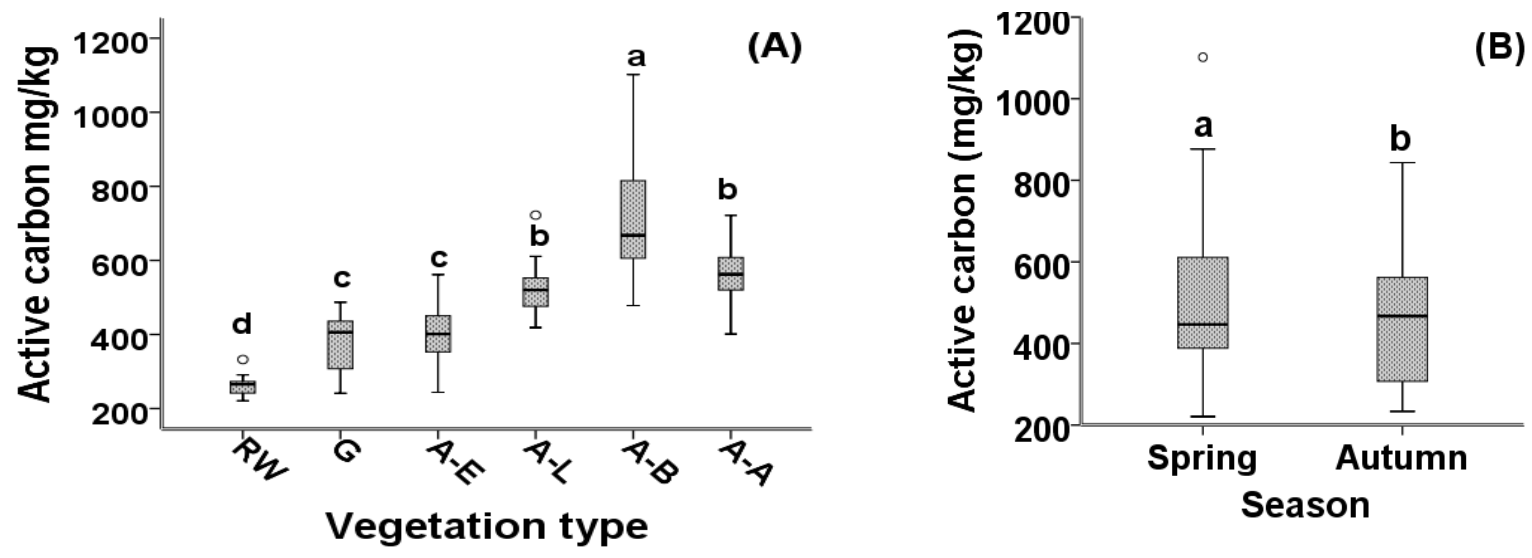

Figure 2 . The effects of vegetation type (A) and season (B) on active carbon.

\section{Soil carbohydrates}

The variation of carbohydrate contents in different vegetation types is very similar to that of total organic carbon, in that A-B and A-A exhibited the highest (5843 and $5258 \mathrm{mg} / \mathrm{kg}$, respectively) and RW showed the lowest (1937 mg/kg) carbohydrates (Figure 3A). Spohn and Gianni (2011) reported that conversion of rangeland to farmland resulted to $62 \%$ decline in soil carbohydrates over 110 years $(32.6$ to $12.2 \mathrm{mmol} / \mathrm{kg}$ ). The woody, not easily decomposible litter in A-A vegetation type explains the high content of carbohydrates in this site; low rate of humification entails increased soil carbohydrates. Greenland and Oades (1975) found decresed levels of sugers as a function of increased rates of humification. The seasonal variation of soil carbohydrates was not significant (Figure 3B).
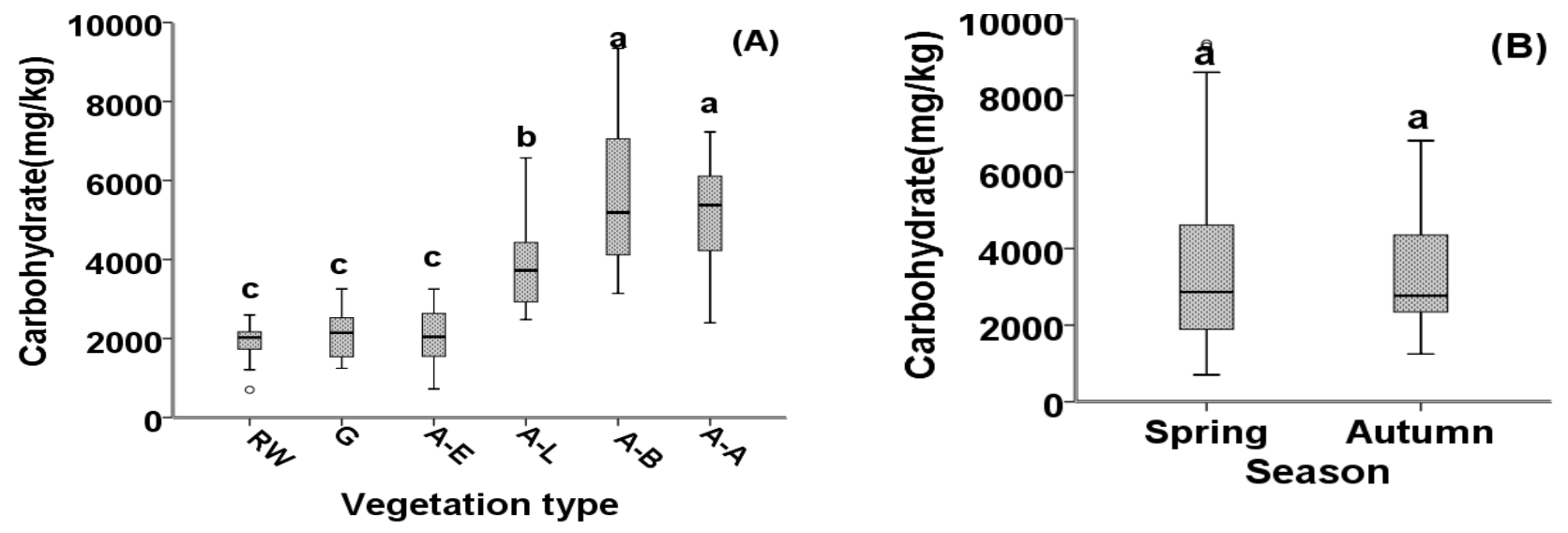

Figure 3. The effects of vegetation type (A) and season (B) on carbohydrate.

\section{Basal microbial respiration}

The highest microbial activity, revealed by basal microbial respiration, was observed in A-B and A-A sites, mainly due to the high canopy cover, species richness (Table 1) and soil organic matter; no significant defference was detectable between other vegetation types (Figure 4A). Total organic matter and labile organic carbon inputs are lower in A-L, A-E and G sites; this may explain the reduction of microbial activity in these vegetation types. An important part of soil respiration is attributed to the decomposition plant residues, thus soil respiration usually decreases by grazing and harvesting of plant residues, decrease and by adding residues increases (Boone et al., 1998; Jonasson et al., 2004). The seasonal variation of basal respiration was not significant (Figure 4B). 

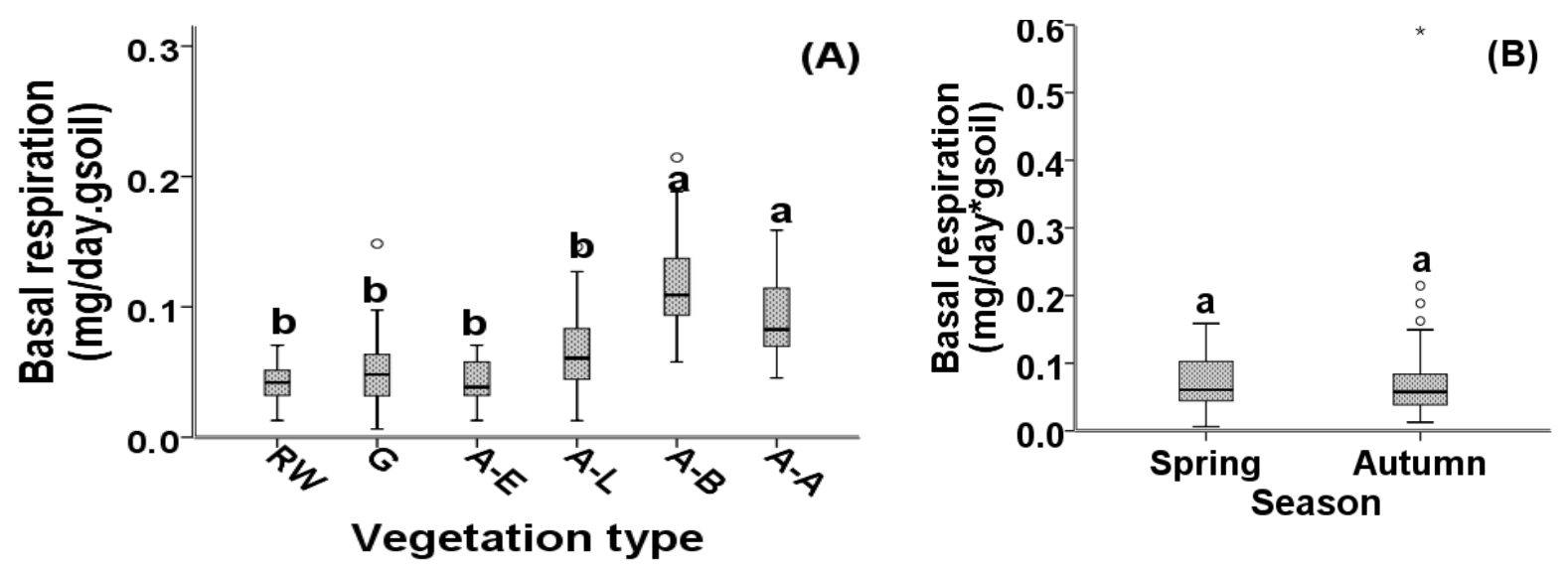

Figure 4. The effects of vegetation type (A) and season (B) on basal respiration.

\section{Soil quality indicator interrelationships}

Significant linear correlations were observed between soil quality indicators. In autumn, active carbon is highly correlated with carbohydrates $(\mathrm{r}=0.701)$ and basal respiration (0.441) (Table 3). Moreover, compared to the autumn, stronger correlations were found in spring time. Laible carbon fraction usually increases in spring due to the higher root and microbial secretions, which in turn have a positive feedback on microbial activity. This explains high correlation of basal microbial activity with carbohydrates and active carbon, the most available form of organic matter for microbial decomposition. Weil et al (2003) reported that active carbon is significantly correlated with basal respiration, microbial biomass and soluble carbohydrates. They found that basal respiration and active carbon are more strongly correlated than basal respiration and total organic carbon.

Table 3. Pearson correlation between selected soil quality indicators.

\begin{tabular}{|c|c|c|c|c|c|c|}
\hline & \multicolumn{3}{|c|}{ Autumn } & \multicolumn{3}{|c|}{ Spring } \\
\hline & $\begin{array}{c}\text { Total organic } \\
\text { carbon }\end{array}$ & $\begin{array}{l}\text { Active } \\
\text { carbon }\end{array}$ & Carbohydrates & $\begin{array}{l}\text { Total organic } \\
\text { carbon }\end{array}$ & $\begin{array}{l}\text { Active } \\
\text { carbon }\end{array}$ & Carbohydrates \\
\hline Active carbon & $0.242^{*}$ & 1 & & $0.843^{* *}$ & 1 & \\
\hline Carbohydrates & $0.289^{*}$ & $0.701^{* *}$ & 1 & $0.678^{* *}$ & $0.793^{* *}$ & 1 \\
\hline Basal respiration & 0.183 & $0.441^{* *}$ & $0.415^{* *}$ & $0.802^{* *}$ & $0.752^{* *}$ & $0.737^{* *}$ \\
\hline
\end{tabular}

\section{Conclusion}

Vegetation types had significant effects on selected soil quality indicators, so that, A-A and A-B sites exhibited the highest soil quality, mainly because of higher vegetation cover, litter, and plant diversity in these sites. RW, followed by A-E site, demonstrated the lowest soil quality due to the tillage practices and low plant residue inputs in the first case, and overgrazing of vegetation cover and litter in the second.

Total soil organic carbon and active carbon were significantly higher in spring time compared to autumn. Seasonal changes of basal microbial respiration and carbohydrates were not statistically significant. In autumn, due to low temperature, humification process is low, the other side RW was fallow in spring and amount of carbohydrate is reduced in fallow periods, in the resulting amount of carbohydrate in autumn was greater than spring.

\section{References}

Anonymous, 2008. Meteorological Information Center of Iran (Hamadan), Statistics and information Meteorological Station of Hamedan. Available at: www.hamedanmet.ir.

Bahrami, A., 2012. Modeling soil organic carbon dynamics using APEX Gonbad paired watersheds. Master's thesis. Bu Ali Sina University. Faculty of Agriculture. 
Boehm, M.M., Anderson, D.W., 1997. A landscape-scale study of soil quality in three prairie farming systems. Soil Science Society of America Journal 61(4): 1147-1159.

Boone, R.D., Nadelhoffer, K.J., Canary, J.D., Kaye, J.P., 1998. Roots exert a strong influence on the temperature sensitivity of soil respiration. Nature 396: 570-572.

Dubois, M., Gilles, K. A., Hamilton, J. K., Rebers, P. A., Smith, F., 1956. Colorimetric method of determination of sugars and related substances. Analytical. Chemistry 28: 350-356.

Franzluebbers, A. J., Haney, R. L., Honeycutt, C. W., Arshad, M. A., Schomberg, H. H., Hons, F. M., 2001. Climatic influences on active fractions of soil organic matter. Soil Biology and Biochemistry 33(7-8): 1103-1111.

Franzluebbers, A.J., 2010. Soil organic carbon in managed pastures of the southeastern United States of America. In: Abberton, M., Conant, R., Batello, C. (Eds.), Grassland Carbon Sequestration: Management, Policy and Economics. Integrated Crop Manage, vol. 11. United Nations Food Agric, Org., Rome, Italy, p. 163-175.

Graham, M.H., Haynes, R.J., Meyer, J.H., 2002. Soil organic matter content and quality: Effects of fertilizer applications, burning and trash retention on a long-term sugarcane experiment in South Africa. Soil Biology and Biochemistry 34, 93-102.

Greenland, D J., Oades, J.M., 1975. Saccharides. In: Gieseking, J. E. (Eds), Soil Components. Vol. I. Springer-Verlag. New York. pp. 213-261.

Gregorich, E. G., Drury, C. F., Ellert, B. H., Liang, B. C., 1997. Fertilization effects on physically protected light fraction organic matter. Soil Science Society of America Journal 61: 482-484.

Haynes, R.J., Beare, M.H., 1996. Aggregation and organic matter storage in mesothermal, humid Soils. In "Structure and Organic Matter Storage in Agricultural Soils. In: Carter, M. R., Stewart, B. A. (Eds), pp. 213-262. CRC Press, Boca Raton, FL.

Isermeyer, H., 1952. Eine einfache Methode sur Bestimmung der Bodenatmung and der carbonate in Boden. Z. Pflanzenernähr Bodenkunde 56: 26-38.

Islam, K.R., Weil, R.R., 2000. Land use effects on Soil quality in a tropical forest ecosystem of Bangladesh. Agriculture, Ecosystems and Environment 79: 9-16.

Jonasson, S., Castro, J., Michelsen, A., 2004. Litter, warming and plant affect respiration and allocation of soil microbial and plant C, N and P in Arctic mesocosms. Soil Biology and Biochemistry 36: 1129-1139.

Parton, W.J., Schimel, D.S., Cole, C.V., Ojima, D.S., 1987. Analysis of factors controlling soil organic matter levels in Great Plain grassland. Soil Science Society of America Journal 51: 1173-1179.

Spohn, M., Giani, L., 2011. Total, hot water extractable, and oxidation-resistant carbon in sandy hydromorphic soilsAnalysis of a 220-year chronosequence. Plant and Soil 338: 183-192.

Walkley, A., Black, I. A., 1934. An examination of Degtjareff method for determining soil organic matter and a proposed modification of the chromic acid in soil analysis. Experimental Soil Science 79: 459-465.

Weil, R.R., Islam, K.R., Stine, M.A., Gruver, J.B., Samson-Liebig, S.E., 2003. Estimating active carbon for soil quality assessment: a simplified method for laboratory and field use. American Journal of Alternative Agriculture 18: 3-17. 